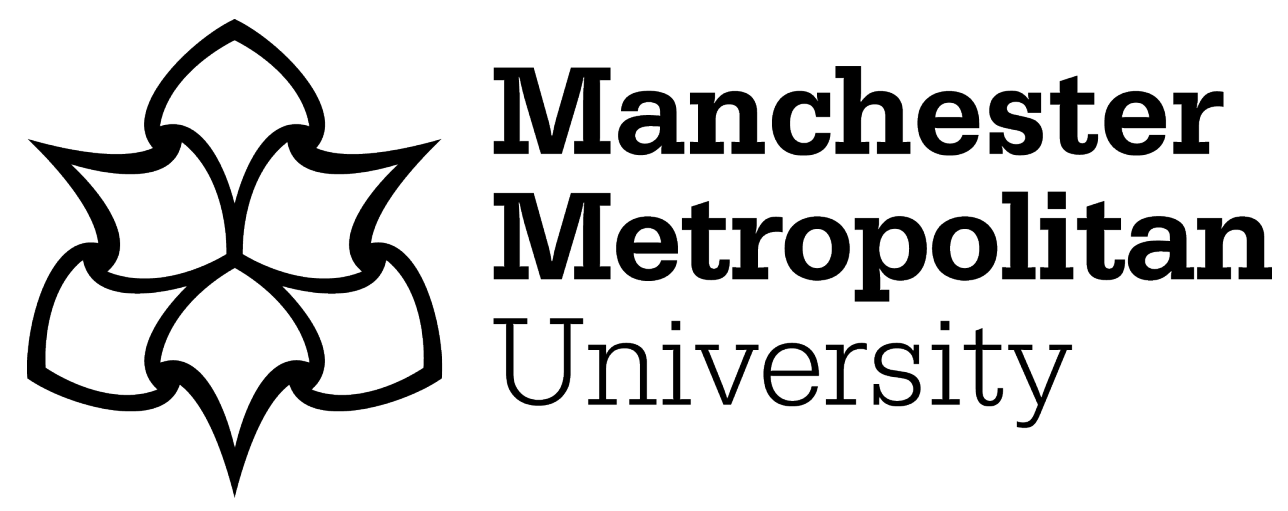

Gazzola, P, Amelio, S, Papagiannis, F and Michaelides, Z (2021) Sustainability reporting practices and their social impact to NGO funding in Italy. Critical Perspectives on Accounting, 79. p. 102085. ISSN 1045-2354

Downloaded from: https://e-space.mmu.ac.uk/625226/

Version: Accepted Version

Publisher: Elsevier

DOI: https://doi.org/10.1016/j.cpa.2019.04.006

Usage rights: Creative Commons: Attribution-Noncommercial-No Derivative Works 4.0

Please cite the published version 


\title{
Sustainability reporting practices and their social impact to NGO funding in Italy
}

\author{
Patrizia Gazzola ${ }^{\mathrm{a}, *}$, Stefano Amelio ${ }^{\mathrm{a}}$, Fragkoulis Papagiannis ${ }^{\mathrm{b}}$, Zenon Michaelides $^{\mathrm{c}}$ \\ ${ }^{a}$ University of Insubria, Department of Economics, via Monte Generoso 71, 21100 Varese, Italy \\ ${ }^{\mathrm{b}}$ Liverpool John Moores University, Liverpool L3 5UG, UK \\ ${ }^{\mathrm{c}}$ Manchester Metropolitan University, Manchester M15 6BH, UK
}

\section{A R T I C L E I N F O}

\section{Article history:}

Received 30 April 2018

Revised 14 April 2019

Accepted 24 April 2019

Available online $\mathrm{xxxx}$

\section{Keywords:}

Social impact disclosure

NGO funding

Sustainability reporting

Social impact measurement

\begin{abstract}
A B S T R A C T
This study analyses the growing social trends of sustainability reporting practices in non-governmental organisations (NGOs). Taking a preliminary step toward NGO funding, we consider the current lack of information disclosure in existing reporting practices, which are diverse and unsustainable. We investigate key organisational information in order to discover any potential links between funding sources and disclosure practices. In Italy, today there is an on-going effort to encourage public engagement in civil society. A percentage-tax law allows taxpayers to dedicate 'cinque per mille' (one-half percent) of their income to NGOs, which is then deducted from their tax obligation (Hereafter, ' 5 per thousand'). Our primary research objective is to understand if there is a link between the ' 5 per thousand' donations that NGOs receive for providing social impact, and their reporting practices. Therefore, we critically analyse if and how sustainable reporting practices are achieved within the top 100 most funded NGOs that receive the ' 5 per thousand' donation. We examine public data from official government records published by the Italian Revenue Agency. The findings suggest that sustainability reporting offers a number of financial and social advantages, including social impact that builds trust towards the idea of civil society and its funders.
\end{abstract}

(c) 2019 Elsevier Ltd. All rights reserved.

\section{Introduction}

In many countries around the world, non-profit organisations are required by law to comply with a minimum level of transparency (Parsons, 2017). The Italian 'third sector' industry exceeds 60 billion euros per year and includes all non-profit organisations, which are primarily socially-focused organisations. Non-governmental organisations (NGOs) are the largest category of non-profit organisations (NPOs) in Italy. The term is not used consistently in Italy, as NGOs and non-profit organisations (NPOs) have many more similarities than differences (Ivanenko, 2015; Willetts, 2010). Most of these NGOs adopt diverse practices in their sustainability reporting although they receive ' 5 per thousand' tax-free funding from several investors. Donors can choose among charities, social-promotion associations, formally-recognised associations, entities dedicated to scientific research and healthcare, universities, municipal social services, and other non-profit organisations. Therefore, the challenge of facing growing demand of accountability in the wake of international

\footnotetext{
* Corresponding author.

E-mail addresses: patrizia.gazzola@uninsubria.it (P. Gazzola), stefano.amelio@uninsubria.it (S. Amelio), F.Papagiannis@ljmu.ac.uk (F. Papagiannis), z.michaelides@mmu.ac.uk (Z. Michaelides).
} 
corporate and non-profit organisational scandals remains. An increased demand for transparent reporting and corporate governance has given rise to numerous international efforts to promote non-profit accountability (Koppell, 2010; Hielscher, Winkin, Crack, \& Pies, 2017). Currently, in Italy, not all stakeholders require publicly disclosed data for organisational monitoring. Therefore, it is difficult for the public to access this data and asses the social impact of each NGO.

In the 1990s, the role of NGOs in the field of social welfare accelerated. This acceleration has been attributed to the failure of governments to deliver development and to implement the principles of social justice and social welfare. In other words, NGOs had to step in and deliver where the government had failed. NGOs are established with the aim of providing social value by implementing different projects and activities; the problem, however, is how to finance these organisations.

In this regard, Italy established the so-called ' 8 per thousand' in 1985 to fund a number of NGOs. This idea of a percentage-tax designation was discussed among various stakeholders. In the early Nineties, the newly-evolving countries in Central and Eastern Europe began to consider introducing a similar concept to finance church and civil society. The mechanism was first formally adopted in Hungary in 1996. Next, the Slovak Republic in 1999, Lithuania in 2002, and Romania and Poland in 2003 introduced other versions of the mechanism to finance the normalisation of the relationship between church and state (Radinger, 2017).

The mechanism has also been considered, at least to some extent, by eight other post-communist countries, namely Croatia, the Czech Republic, Estonia, the Former Yugoslav Republic of Macedonia, Moldova, Serbia, Ukraine, Georgia, and others continue, subject to national debate. In 2015, Moldova approved a law to install the mechanism following the Romanian example. Japan, Spain, and Portugal have already introduced similar tax-designation systems (Argenti \& Saghabalyan, 2017). The term 'non-profit organisations', where NGOs remain the largest category in Italy, indicates an organisational type that does not primarily aim to make a profit, although, in reality, profits are often achieved (Salamon \& Anheier, 1997). In any case, the profit accumulated by non-profit organisations is not distributed to shareholders; instead, it is reinvested in projects and activities that relate to the organisation's goals. Non-profit institutions take many forms, but the common denominator is a conscious attempt to disengage from the for-profit corporate world (Badelt, Meyer, \& Simsa, 1999). Although the aim of non-profit organisations is not profitability, they certainly aim towards financial stability in the long run. They also have a clear focus on their mission statements towards a certain level of 'social impact'. In this exploratory research, we highlight the importance of a specific non-profit organisational type of NGO, in an effort to provide the community with pertinent information on the nature of its managerial activities.

Presently, their particular socioeconomic functions cannot be highlighted effectively using informational tools designed to meet the needs of business (Tremblay-Boire \& Prakash, 2015). Thus, social and philanthropic management cannot be valued according to economic parameters (Costa \& Pesci, 2016). Therefore, it would be appropriate to develop an information process that involves the social nature of all of their elements (e.g., public relations, stakeholders' interactive communications, dialogue and coordination of the various social areas). In socio-economic activities, transparency is key (Behn, DeVries, \& Lin, 2010). Transparency requires the wide availability of useful information about a non-profit organisation's governance, financial position, and general performance (Bushman \& Smith, 2003). It relates to the amount of organisational information publicly disclosed and its honest and prompt dissemination (Michelon, Pilonato, \& Ricceri, 2015). The consequences of open communication and visibility of action are immediately evident, as NGOs obtain social legitimisation for such initiatives (Gazzola \& Meo Colombo, 2011). A common way of achieving public disclosure and data dissemination is through the internet. For NGOs, it is fundamental, but not sufficient, to release their mission and objectives publicly. They have to engage their external stakeholders in a multilateral communication strategy that covers all of the organisation's actions and results (Saxton \& Guo, 2011). Donors require explanations of both the quantitative and qualitative impact of their donations as evidence of the fair allocation of the NGO's funding and how the organisation meets its social aims.

For an NGO to assess the social impact of a fund, it needs to secure and maintain its donors, provide a high level of transparency, and actively support its overall mission. A comprehensive way of providing transparency is to produce an annual report (Meyer, Ferrari \& Zoebeli, 2012; Zainon, Hashim, Yahaya, \& Atan, 2013). In an annual report, the organisation can graphically and compellingly reveal the highlights of its achievements, services, and financial records. Moreover, it can make these readily available to the public by posting them on the website. Nevertheless, this administrative practice for information disclosure is expensive for a small-to-medium-size organisation (Friedman \& Miles, 2006). The more an NGO ensures that its organisational practices are accountable and transparent, the more trustworthy and reliant the public, donors, constituents, and regulators perceive it to be. The acceptance of stakeholder theory (Freeman, 1984) underlines the fact that organisations have to redefine their competitive strategies and the way they manage social activities. Multiple-constituency theory (Kanter \& Summers, 1987) supplements Freeman's approach (1984), revealing the need for public evaluation and stakeholders' engagement to legitimise non-profit activities. As a result, external stakeholders' communication strategy represents an important opportunity for these organisations to increase their social acceptance and offer their own points of view, supported by information that is objective, understandable, and verifiable.

Since 2006, an Italian percentage-tax resignation law allows NGOs to enjoy funding derived from taxes paid by citizens when making tax returns (Law No. 266/2005). This tax-measure allows taxpayers to donate a portion of their income tax (equal to 5 per thousand of their total income) to support the service sector (Gazzetta Ufficiale, 2006). This socio-politically-oriented government law is a form of direct support to all NGOs in Italy (Lodi, 2012). 
The choice to donate 5 per thousand is absolutely voluntary and not mandatory. For the taxpayer, it does not generate a greater outlay, as the amount of 5 per thousand is separated from the Income Persone Fisiche model (IRPEF) debt. In the tax declaration, whether it is the IRPEF model or any other declaration model available, the taxpayer finds an attachment with six boxes. These boxes are available to taxpayers to indicate the tax code of the institution to donate 5 per thousand and the space to affix their signatures. In the absence of these two indications, the payment of 5 per thousand is cancelled and remains in the coffers of the State. Research shows a diverse and often a voluntarily disclose of NGOs information relating to social and environmental issues. Therefore, it is evident that NGOs' commitment to such disclosure practices is inadequate and potentially compromises their financial viability (Yesudhas, 2019). Therefore, there is a lack of sustainable approaches to informational dissemination practices and their impact on NGO funding. As a result, public disclosure of financial and operational information for an NGO receiving 5 per thousand is essential. This type of information disclosure is fundamental for on-going and permanent capital funding, and it leads to well-informed donating decisions. Public availability of NGOs' financial information is important because lack of accessibility may result in loss of public confidence (Gazzola \& Ratti, 2014; Gazzola, Ratti, \& Amelio, 2017).

This study presents an empirical analysis of NGOs that receive this donation in Italy. We analyse the transparency and the accountability levels of the 100 most-funded NGOs that have received the contribution of ' 5 per thousand' and assess whether or not they prepare a sustainability report. Our purpose is to understand if there is a link between the " 5 per thousand' that organisations receive and the public disclosure of a sustainability report. To analyse this connection, we tested three assumptions over a five-year time period. In particular, the study examines whether these 100 most-funded NGOs report that they have received such a contribution and whether this communication strategy has had a positive impact on the contributions they received in subsequent years.

Among the most important findings are the following: (i) the higher the actual amounts or instances reported of funds received, the higher the transparency level achieved, and (ii) the higher the instances reported of funds received, the lower the accountability level through published sustainability reports. Paradoxically, however, the findings suggest that a higher degree of social accountability for NGOs is related to lower amounts of funds received. Nevertheless, a higher degree of accountability leads to a higher level of transparency, which offers a number of financial and social advantages, making accountable and transparent organisational processes worth more than their associated costs.

\section{Literature review}

The growing trend of non-profit organisations to achieve organisational growth and continuity is of prominent importance (Reimann, 2017). Therefore, NGOs must demonstrate respect for the environment in which they operate, safeguard their work and human resources' needs, and satisfy the expectations of all of the social actors within their sphere of influence (Vlad, 2012). Such an approach will lead them to behave in a way that is consistent with the ethical and social values of their communities (Colombo \& Gazzola, 2014). It will also assist in the development of impactful and transparent information disclosure that underscores the NGO's commitments and achievements (Newson \& Deegan, 2002; O’Dwyer, Unerman, \& Bradley, 2005; Momin, 2013; Tremblay-Boire \& Prakash, 2015). In recent years, non-profit organisations have supplemented their annual financial accounts with a statement that integrates traditional information with other measures and indices as well as environmental, ethical, and social data, relating to sustainability reporting (Unerman, Bebbington, \& O’Dwyer, 2010; Simnett, Vanstraelen, \& Chua, 2009; Berthelot, Coulmont, \& Serret, 2012). The Global Reporting Initiative (GRI) is the most salient and common guiding set of principles for reporting in the NGO sector (GRI, 2010); it enables organisations to measure and report their sustainability performance (GRI, 2011). Currently, this initiative to measure and disclose sustainability performance is the most widely used internationally. While the GRI has received strong global support in academic literature (Brown, de Jong, \& Levy, 2009; Morhardt, Baird, \& Freeman, 2002), there is also a fair amount of criticism of this initiative (Boiral, 2013). Presently, many NGOs voluntarily disclose information on their ethical behaviour and their public relations regarding social and environmental issues (Striebing, 2017). Such disclosures enhance their corporate economic profile and credibility, reflecting the overall value of the institution. However, it remains an almost exclusively voluntary practice. As a result, there is not a consistent standard imposed for drafting these disclosures. Therefore, every company has full freedom to select the model that is most popular among different national or international formats (Gazzola, 2012).

In considering the implementation of a disclosure communication strategy, it is necessary to define the social and environmental characteristics being measured. Alongside the economic and financial communication tools that allow companies to nurture earnings and competitiveness, social consensus and social legitimacy should be present and integrated into accountability concerns. The preparation of a social communication document (Adams, 2017) should focus on uniting the pursuit of the mission with the collective interest. As a result, business communication could be improved in certain circumstances, depending on the corporate disclosure strategy. Finally, sustainability reporting combines social legitimacy and financial growth of the NGOs, as they are considered multi-stakeholder organisations 'par excellence' (Rey, Alvarez \& Bello, 2013). They are facing the growing importance of considering stakeholders' expectations and potential societal impacts of their activity, in order to survive in the long-term. Crespy and Miller (2011) analysed the data from Fortune 250 corporations and the Forbes 200 NGOs regarding their commitment to and development of sustainability practices. Their findings reveal that NGOs' commitment to such disclosure practices is inadequate, thus undermining 
their claims of legitimacy in their quest to participate in corporate governance. The following are different reasons why NGOs should implement sustainability disclosure practices:

(i) To improve their reputation.

Sustainability reporting helps to build trust with stakeholders (Keating \& Thrandardottir, 2017) and take a proactive managerial approach toward the NGO's reputation. Various surveys corroborate this thesis. In particular, a 2011 study showed that greater transparency and clarification of positive actions allow organisations to create and consolidate the public's trust in them (BSR, 2011). A 2013 study based on interviews conducted by Boston College's Center for Corporate Citizenship and the Ernst \& Young Corporation revealed that more than 50\% of the companies who published sustainability reports have seen an improvement in their reputations (Ernst \& Young, 2012).

(ii) NGOs have an economic, social, and environmental impact, and they are ethically obliged to sustain and improve it.

To understand, manage, and improve their triple-bottom-line impacts as an organisation, NGOs aim to increase the effectiveness of their social and environmental programs in an effort to focus on their 'core mission'. They should also communicate their social impacts to internal and external stakeholders (e.g., employees, clients, donors, government bodies, and communities) in order to share best practices and encourage similar improvements from others (Arenas, Lozano, \& Albareda, 2009).

(iii) NGOs could have corporate demands that they are not willing to cope with.

There is a strong link between NGOs and for-profit corporations in terms of meeting their market needs. Specifically, as for-profit companies often have no economic interest in producing particular types of goods and services, NGOs should bridge that production gap and offer these goods and services. Therefore, they could act as dynamic collaborators in both business and social community activities, providing sustainable initiatives. Sometimes, NGOs criticise large corporations for opaque disclosure of their operations (e.g., the Nestlé scandal) (Ionescu-Somers \& Enders, 2012). Whether NGOs are allies or critics, their own credibility is tarnished when they publish similarly unsustainable reports or disseminate information in a trivial manner.

(iv) NGOs need to be financially viable.

As with all non-profit organisations, NGOs are prohibited from distributing their profits, but they are not prohibited from making a profit. On the contrary, it is desirable that they are profitable and reinvest their retained earnings in the pursuit of social improvements. Therefore, while the realisation of profits is not their main goal, they need to be financially viable. The business case for corporate social responsibility reporting includes metrics for cost savings, including efforts in energy efficiency, waste reduction, recycling, among others. Making or saving money is an enormous motivator for sustainability (Zald, 2017). Such savings would definitely appeal to NGOs, where budgets are fixed and non-negotiable (Valencia, Queiruga, \& González-Benito, 2015).

\section{(v) Attract talented human resources.}

Corporations engage in sustainability reporting, primarily, as an increasingly important tool for investment attraction (Bolton \& Guest-Jelley, 2012) and talent management. Talented individuals from the nation's best schools often scrutinise the corporate citizenship of companies as a criterion for working with them. Large corporate pay checks and hefty vacation plans are no longer enough to attract talented human resources. University graduates want to work for companies that are doing well by doing good. Thus, the same holds true for NGOs, whose need for investors and talented individuals is also vital. In such organisations, the same argument is also valid for volunteers and community stakeholders. Furthermore, high levels of transparency increase the economic, social, and environmental drivers of their sustainability practices (Anheier, Haß, Then, Beller, \& Wehrsig, 2011).

\section{(vi) Attract donors.}

Donors are overloaded with requests for donations from multiple organisations. Therefore, they could be influenced and decide to donate to organisations that publish a form of sustainability report. In fact, for donors, this report represents a guarantee that their donation will be used in an appropriate and consistent manner (Rauh, 2010). The institution would thus be able to achieve a competitive advantage over opaque organisations in the 'fund-raising war'. 
(vii) Meeting employees' expectations.

Employees represent one of the main categories of internal stakeholders addressed by the social accountability process. Such social interactions between corporations and their employees increase employee loyalty and decrease absenteeism (Ernst \& Young, 2012). As a result, sustainability reporting drives employee engagement and attracts human capital. Therefore, NGOs must engage in socially responsible practices, delivering sustainable impact both internally and externally.

(viii) Create a social tool for upgrading the process of stakeholder dialogue and empowerment.

Sustainability reporting is an opportunity to reflect on corporate social responsibilities and stakeholders' commitments. High levels of transparency and information disclosure are closely linked (Morsing \& Schultz, 2006; Manetti, 2011).

(ix) Commit to sustainability disclosure.

The number of organisations and individuals asking NGOs about their social and environmental performance has grown tremendously during the past decade. Investors, customers, employees, community residents, and advocates are all voicing their concerns and questioning organisations' commitment to responsible conduct (Rodríguez, Pérez, \& Godoy, 2012).

(x) Ensure sustainability through internal governance, ethics, and risk management practices.

Such a reporting process could help organisations to reflect on realistic and feasible steps toward building a viable future, which is the challenge (Baumgartner \& Rauter, 2017). According to the line of reasoning above, (e.g., i, ii, vii, viii and ix), high levels of transparency and public accountability are practical and increasingly credible organisational tools used to demonstrate an organisation's commitment to socioeconomic development to a diverse range of stakeholders. Sustainability reporting is an interactive communication approach that is important for internal stakeholders (e.g., workers, managers, and other employees) and external stakeholders (e.g., suppliers, customers, social stakeholders, and community actors) (Dumay, Guthrie, \& Farneti, 2010). It allows organisational stakeholders to understand that there is a strong interdependence between economic and socio-political factors, a bond that has become increasingly timely, uniform, transparent, and complete and is deeply-linked to company decisions as well as being a consequence of them (Browne \& Nuttall, 2013). Simultaneously, donors could be strongly influenced by high levels of organisational transparency, particularly by the presence of a voluntarily published sustainability report.

The following section explains our methodology for examining the NGOs' social accountability, financial data dissemination, and the relationship between their levels of transparency and their accountability with regard to the creation of sustainable social impact.

\section{Research methodology}

This study analyses the domain of information-disclosure practices in the third sector. Specifically, it focuses on sustainability reporting in Italian NGOs that receive the ' 5 per thousand' donation as a pertinent endeavour within the overall social framework of information disclosure. As NGOs have a 33\% share in the Italian third-sector industry (almost 20 billion euros), their social impact and its relation to the information disclosure practices of this specific tax relief law are of major importance (http://censimentoindustriaeservizi.Istat.it). Therefore, we analyse the disclosure practices of the first 100 NGOs that received the highest donations from ' 5 per thousand', using information from their websites or other data available on the Internet. Thus, we have formulated the following assumptions:

Assumption 1: The higher the actual number or instances of reported funds received, the higher the transparency level derived from published information on websites, including organisational funding and donations.

Assumption 2: The higher the actual number or instances of reported funds received, the higher the accountability level derived through the publication of sustainability reports.

Assumption 3: The NGOs that report funds received by value, as derived from published information on their websites, including amounts received from the ' 5 per thousand resignation' tax, demonstrate higher levels of accountability through the publication of sustainability reports.

To address the above assumptions, we also examine the ' 5 per thousand' published report to see if it positively impacts the contributions received in subsequent years. Furthermore, in relation to the second assumption, it is also interesting to examine whether our first line of reasoning statement (i), that NGOs improve their reputation by implementing sustainability disclosure practices, is verified or not. In particular, we examine how sustainability reporting helps to build trust with stakeholders. We considered the positive impact on the contribution received as an indicator of an NGO's reputation (Will \& Pies, 2017). After extracting and selecting the first 100 NGOs, we categorised their publicly disclosed 
documentation and built our database. Finally, we implemented our statistical analysis with the Statistical Package for Social Sciences (SPSS statistics software).

By adopting an exploratory methodology, this study tests the three aforementioned assumptions and critically analyses the findings. Through our analysis, we discovered a significant gap relating to the publicly-disclosed data of NGOs. Specifically, we aim to discover the relation between sustainability reporting and disclosure practices of an NGO and its received-funding from the public, donors, constituents, and other stakeholders. Consequently, we continue to explore whether these NGOs publish any form of sustainability reporting (Lehman, 2007). Given the ability of the NGOs' financial statements to provide a social profile, the research engages in the following specific selection criteria for data analysis. These criteria include: (i) the 100 most-funded NGOs, (ii) the years that these NGOs publicly report data, and (iii) the amount of funding they received.

The type of study adopted herein is a panel or longitudinal study, and we analyse longitudinal data, which are commonly used in econometrics. In our study, the time-period of the data extends over five years. Since data were reported for each NGO every year, the data set is described as a balanced panel, and, since data sets include objects with a single observation point in time, we adopted a long-format data structure.

We decided to analyse Italian NGOs for several reasons. Firstly, we wanted to uncover the dissemination and relationship to public funding. Secondly, we wanted to examine their financial data dissemination and their relationship to public funding. Thirdly, we wanted to examine the relationship between transparency and accountability levels and the creation of sustainability reporting (Joseph, 2012).

To obtain our data, we extracted the 100 most-funded NGOs from the Italian Revenue Agency (Agenzia delle Entrate) website, the government agency that deals with the management of taxes (Agenzia Entrate, 2018). In particular, the agency regularly publishes a list containing the recipients of the ' 5 per thousand' funding. The last published list (updated on 29 December 2017) concerns the 2015 financial year. The lists for 2016 and 2017 financial years have not yet been published; this delay occurs because it takes a long time for the agency to collect the data. In addition, the submission deadline for 2016 tax declarations was January 2018. The collected data from this list is public and freely accessible. These are the circumstances of our specific research limitations. Among our research findings, we discovered that, despite demonstrating a certain level of transparency by publishing the amounts or instances of received funds, NGOs fail to demonstrate high levels of accountability because they do not publish any kind of sustainability reports. Second, we could not discover the reasons behind these levels of transparency, as these funded NGOs fail to report this funding. In addition, the same NGOs demonstrate uncertain accountability levels, as they also fail to publish any sustainability reports.

In order to test our assumptions, we measured the following criteria for these 100 non-profit organisations: (i) highest amount of funding received in 2015, (ii) public and transparent dissemination of information relating to social management, and (iii) any form of social accountability based on sustainable reporting.

In order to support the research findings in terms of defining 'low' or 'high' classifications and trends for transparency and social accountability, as discussed in the assumptions, we have adopted the following method for ranking each classification against the number of years for which reporting of data were evident (see Table 1 ).

We consider the levels of transparency and accountability 'low' when the reporting data practices were evident for only one out of five years. We consider the levels of transparency and accountability 'medium' when the reporting data practices were evident for two or three years out of five years. Finally, we consider the levels of transparency and accountability 'high' when the reporting data practices were evident for four or five of the five years of our research horizon. As a result, indexes for transparency and accountability were formulated and the data were grouped into the three categories, as shown in Table 1. Finally, the data were analysed to identify the percentage values of NGOs displaying levels of both transparency and accountability.

\section{The Italian NGOs' case: findings and analysis}

Our research findings provide strong evidence that the first 100 Italian NGOs failed to publicly disclose any form of sustainability reporting. The results of the econometric analysis concerning this study's assumptions relate to three general categories. All of these categories are numerically expressed as percentages in this section's tables and figures. They are as the follows:

Table 1

Classification method of NGO data for transparency and/or accountability against number of years reported.

\begin{tabular}{lll}
\hline Years of data reported for: Transparency Index (T) \& Accountability Index (A) & Transparency Index (T) & Accountability Index (A) \\
\hline $0 ~ \& 1$ & Low transparency (T_LOW) & Low accountability (A_LOW) \\
2 \& 3 & Medium transparency (T_MED) & Medium accountability (A_MED) \\
$4 \& 5$ & High transparency (T_HIGH) & High accountability (A_HIGH) \\
\hline
\end{tabular}


(i) The percentage of non-profit organisations that have a website.

(ii) The percentage of non-profit organisations that prepare and publish a transparent report on their corporate website.

(iii) The percentage of non-profit organisations that report receiving ‘ 5 per thousand' contributions.

Table 2 summarises the results obtained. They are cohesive and tend to be unanimous.

These high percentages indicate the attention that these organisations have received. In order to present the percentage of non-profit organisations that prepare and publish transparent reports and make them available on their corporate websites, we analysed the websites of the sampled non-profit organisations, year by year. The results are presented in Fig. 1 .

In 2011, only 30\% of non-profit organisations presented any form of sustainability report. During the following years, this number gradually increased. Specifically, the percentage rose to $33 \%$ in 2012, to $42 \%$ in 2013 , to $43 \%$ in 2014, and, finally, 45 organisations (out of 100) published some form of sustainability report on their websites in 2015. On the one hand, this trend demonstrates growing attention to social accountability and transparency. On the other hand, this trend is significantly lower among non-profit organisations than among for-profit organisations. In Italy, legislation requires for-profit companies to publish their corporate balance and, since 2014, their sustainability report as well. In fact, in 2014 the European Union issued Directive 2014/95/EU, which introduced the obligation of non-financial information for large undertakings that are public-interest entities. However, this Directive does not include non-profit organisations. For this reason, the level of transparency for the non-profit organisational sector is still problematic.

The percentage of non-profit organisations that reported receiving the ' 5 per thousand' contribution over the period from 2011 to 2015 is presented in Fig. 1. As earlier, these values can be better represented using a bar graph, which clearly highlights this ongoing trend.

The results are quite surprising. The percentage of top- 100 non-profit organisations in Italy that reported receiving the ' 5 per thousand' contribution decreased from 2012 to 2015. The limitation of this value is that it considers the total value of non-profit organisations (i.e., the total 100) instead of the entire number of non-profit organisations that publish any form of sustainability report. The relation between the ' 5 per thousand' report and the presence of sustainability report is of interest here. The results of this unexpected trend are presented in percentage form in the bar graph in Fig. 1. In this case, the value is quite indicative. After 2011 (maximum value), the percentage has gradually increased over the years, except for $2015(-1 \%)$. In general, it seems to be a growing trend.

An increasing number of non-profit organisations tend to comply with data dissemination and transparency by publishing some form of a sustainability report. It is important to highlight that government regulations do not require such an initiative. Therefore, this trend is a clear indication that non-profit organisations are aiming to lure taxpayers by disseminating information about how they allocate and use their funds. At this point, we investigate the existence of any correlation between transparency and accountability trends, in particular, to test assumptions 1,2 , and 3 . The findings of the analysis are summarised in Table 3 below.

The findings indicate a correlation between a higher transparency index $(\mathrm{T})$ and social accountability $(\mathrm{A})$, as shown in the first two columns of Table 3. Specifically, in $85 \%$ of the cases, the transparency index is found to be high, with NGOs effectively reporting receipt of funding over at least four years of the five-year period. A further $9 \%$ of NGOs reported receipt of funding over at least two years of the five-year period, and only $6 \%$ reported receipt of funding in a single year or failed to report any funding at all. Therefore, the first assumption is proved true, since the higher the actual number or instances of reported funds received, the greater the transparency derived from published information on websites, including amounts received from donor organisations.

However, the findings also indicate that the majority of NGOs (57\%) failed to demonstrate credible levels of social accountability. Paradoxically, a large proportion of NGOs with a high transparency index (T) also returned the lowest social accountability (A) figures. Specifically, this describes $44 \%$ of NGOs, which shows that high transparency fails to demonstrate correspondingly high levels of social accountability (see Fig. 2).

The declining trend between the number of NGOs that reported funding while also evidencing social accountability is highlighted in Fig. 2. While 30\% of the top recipients of funding demonstrate transparency and social accountability, 44\% of NGOs acknowledge receiving funding but fail to demonstrate social accountability.

Therefore, assumption 2 is proven untrue, since the higher the instances reported of funds received, the less accountability through published sustainability reports or other kind of reporting.

However, assumption 2 also refers the 'actual amount' of funds received. In this regard, the study shows that assumption 2 is true, since the higher the actual amount of reported funds received, the greater accountability evidenced through sustainability reporting. This is clearly the case for the top $20 \%$ of NGOs, which achieved the highest score for

Table 2

Non-profit organisations: '5 per thousand' contributions. (Internet 2011-2015).

\begin{tabular}{ll}
\hline Year & $\%$ \\
\hline 2011 & 97 \\
2012 & 99 \\
2013 & 100 \\
2014 & 99 \\
2015 & 98 \\
\hline
\end{tabular}




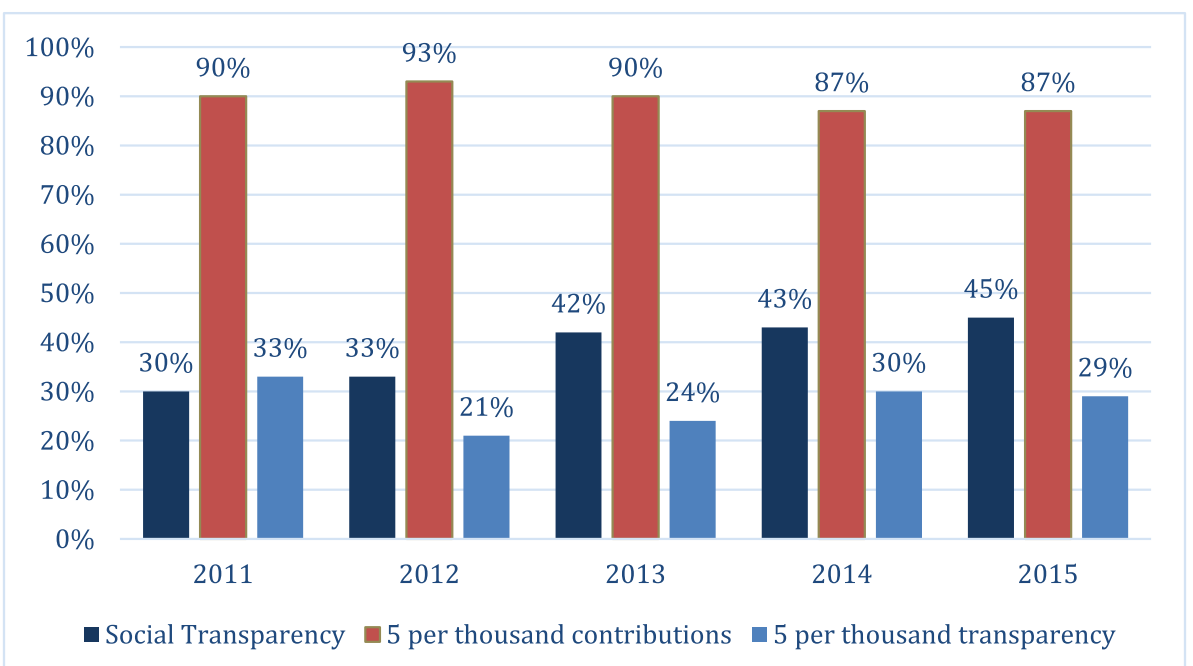

Fig. 1. Non-profit organisations: Social Transparency, ' 5 per thousand' contributions and ' 5 per thousand' transparency among non-profit organisations: 2011-2015.

Table 3

Transparency index (T) vs. accountability index (A).

\begin{tabular}{|c|c|c|c|c|c|}
\hline \multicolumn{2}{|l|}{ TRANSPARENCY INDEX (T): } & \multicolumn{2}{|l|}{ ACCOUNTABILITY INDEX (A) } & \multicolumn{2}{|c|}{$\begin{array}{l}\text { TRANSPARENCY INDEX (T) VS. } \\
\text { ACCOUNTABILITY INDEX (A) }\end{array}$} \\
\hline T_HIGH & $85 \%$ & A_HIGH & 31 & T_HIGH \& A_HIGH & $30 \%$ \\
\hline T_MED & $9 \%$ & A_MED & 12 & T_HIGH \& A_MED & $11 \%$ \\
\hline T_LOW & $6 \%$ & A_LOW & 57 & T_HIGH \& A_LOW & $44 \%$ \\
\hline & & & & T_MED \& A_HIGH & $1 \%$ \\
\hline & & & & T_MED \& A_MED & $1 \%$ \\
\hline & & & & T_MED \& A_LOW & $7 \%$ \\
\hline & & & & T_LOW \& A_HIGH & $0 \%$ \\
\hline & & & & T_LOW \& A_MED & $0 \%$ \\
\hline & & & & T_LOW \& A_LOW & $6 \%$ \\
\hline
\end{tabular}

transparency (T) vs. accountability (A) over five years, while also receiving $71.22 \%$ of the total funding by value. This fact suggests that NGOs that receive lower amounts of funding fail to demonstrate social accountability. Therefore, the study proves that assumption 3 is true, since the NGOs reporting higher transparency of funds received by value do indeed demonstrate more accountability through published sustainability reports.

The analysis unexpectedly also shows that a significant number of NGOs in the medium-to-lower funding receipt group do demonstrate, on average, high-to-medium levels of social accountability together with high levels of transparency (see Table 3). Approximately $20 \%$ of total funding groups are in the medium-to-lower funding group categories, which, as mentioned, show higher than normal levels of social accountability, despite a slight gradient drop in transparency levels (see Fig. 3).

NGOs that receive larger funding amounts do largely demonstrate transparency; the number of instances in which they do not achieve social accountability in proportion to the funding amount they do receive, however, is significant. Considering that $20 \%$ of the NGOs at the bottom of the list of 100 highest recipients of funding receive less than $0.20 \%$ of the total funding pool (the highest receive $28.83 \%$ ), it seems that non-compliance with social accountability initiatives at the top end has significantly more impact than at the lower end.

The Italian mechanism does not financially benefit the whole sector; it only benefits the NGOs that taxpayers choose from a large number of NGOs. In this respect, the taxpayers who participate in 'cinque per mille' mechanism exhibit a form of civic participation. These Italian taxpayers push NGOs to place more emphasis on their communicating practices, especially with their major stakeholders. As NGOs have begun reaching out to the broader public, the necessity of visibility has increased for the organisations receiving ' 5 per thousand' benefits. Informing stakeholders about their projects that benefit society is a key element of transparency, because companies receiving the 'cinque per mille' benefit must ensure they meet public trust criteria (Cabedo, Fuertes-Fuertes, Maset-LLaudes, \& Tirado-Beltrán, 2018). One of the most important elements of the mechanism has been its flexibility and predictability, which contributes to NGOs' stability and channels public funds toward those recipients who would otherwise have limited access to other financial resources. 


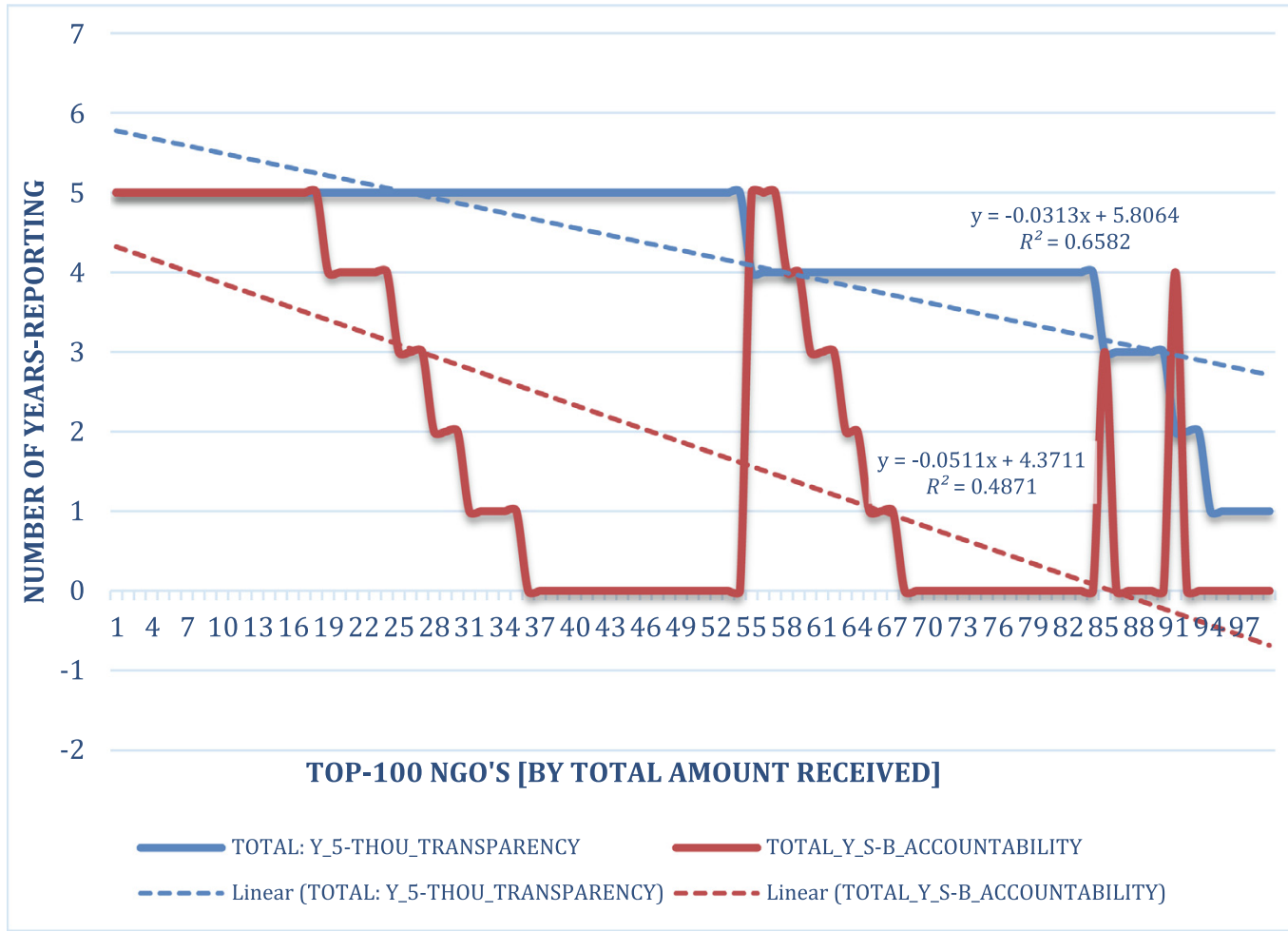

Fig. 2. Top-100 NGO's: Number of years reporting on funding received vs. social accountability reporting.

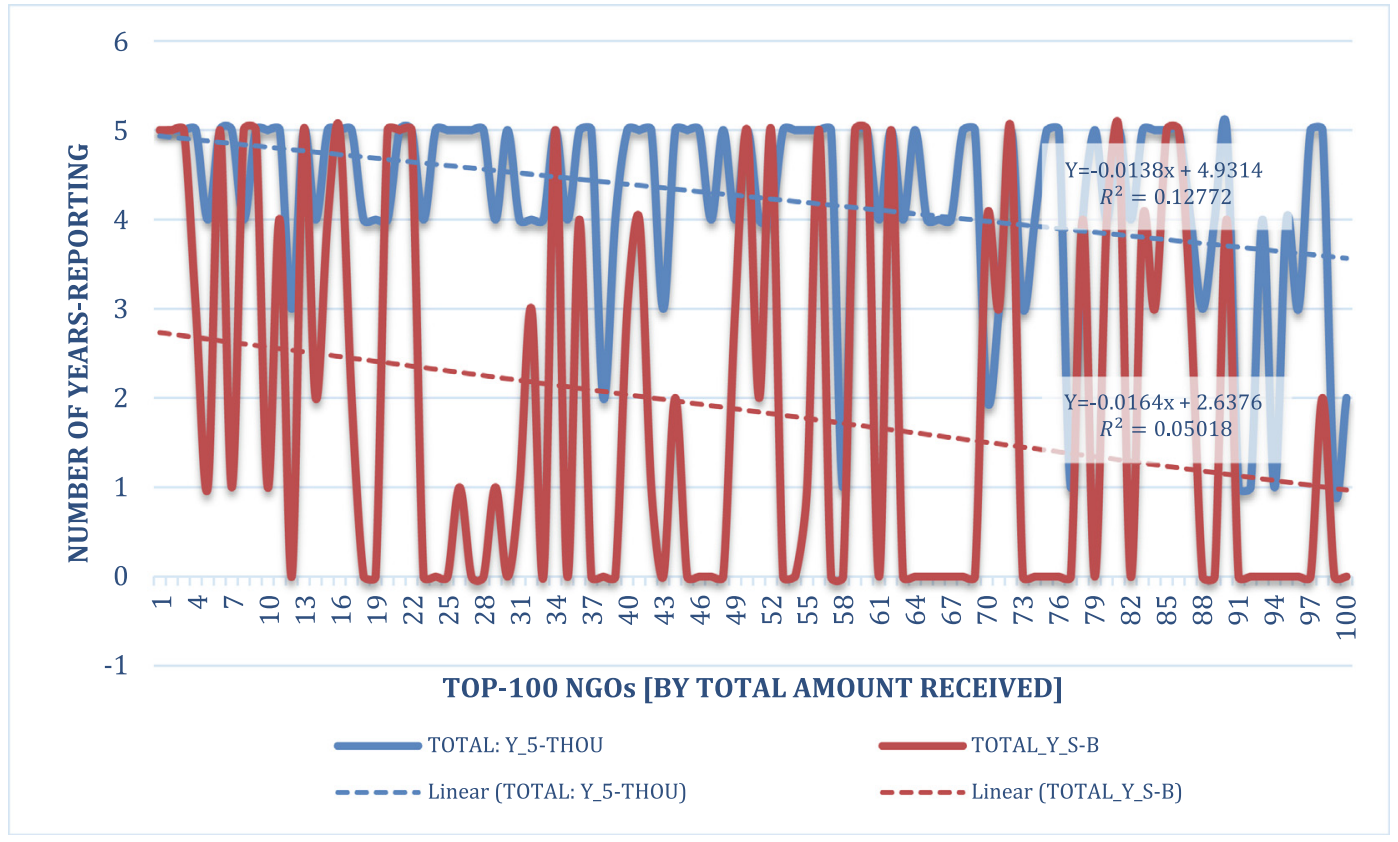

Fig. 3. Top-100 NGOs: Transparency vs. social accountability. 


\section{Conclusions}

Overall, the current work extends the literature on socially accountable and transparent information-dissemination practices and their impact on NGO funding in Italy. We consider this endeavour appropriate and topical, because NGO practices reveal several weaknesses and inadequacies in the existing reporting model, especially concerning a sustainable-reporting approach. The study critically analyses assumptions regarding: (i) the transparency levels of funds received, (ii) the dissemination of information to stakeholders, and (iii) the correlation between funding received from donor organisations and social-accountability levels as evidenced through the publication of sustainability reports. However, there are some research limitations. First, several NGOs that received funding failed to demonstrate any form of sustainability reporting. We could not discover the reason why after receiving funding, these NGOs failed to publicly disclose any form of reporting. Therefore, failure to publish a sustainability report is a noteworthy obstacle for this analysis. Nevertheless, by using publicly accessible data and analysing the corresponding trends, we have undertaken a preliminary step toward addressing the low levels of social accountability and opaque reporting practices in the Italian third-sector economy, specifically in the top-100 NGOs. Findings reveal that the higher the actual amounts or reported instances of funds received, the higher the transparency levels achieved. However, this study also shows that the higher the reported instances of funds received, the lower the level of accountability as evidenced through published sustainability reports. This fact suggests that lower amounts of received funding correlates with NGOs' failure to clearly demonstrate social accountability. Findings also indicate a declining trend between the numbers of NGOs' maintaining a sustainability report and their received funding. In spite of 30\% of the top recipients of funding indicating high levels of transparency and social accountability, the majority of NGOs (44\%) acknowledge receiving funding but fail to demonstrate high levels of social accountability. This is an important finding that future studies need to address further, particularly since the same NGOs continue to demonstrate the same trend year after year.

As an intrinsic element of integrated reporting, sustainability reporting enables organisations to provide high levels of transparency and information disclosure to build the organisation's public profile. Increased levels of transparent reporting and the public disclosure of information made available in digital formats boost confidence in this sector; transparency levels act as a trust-building tool. The stronger the sustainability reporting and disclosure practices of an $\mathrm{NGO}$, the more trustworthy the organisation will be viewed by the public, donors, constituents, and regulators. An emphasis on transparency and accountability helps diverse stakeholders to evaluate organisational performance objectively. Sustainability reporting requires organisations to gather information about processes and impacts that may not have been measured previously. This new set of data can provide knowledge that could contribute to reducing the use of natural resources, increasing efficiency, and improving operational performance. In addition, sustainability reporting can prepare organisations to avoid or mitigate environmental and social risks. These risks may have material and financial impacts on their activities. As a result, NGOs can deliver better social, environmental, and financial value, thereby creating a virtuous circle.

Sustainability reports are not exclusive to large organisations. Any NGO, regardless of size, strategic aim, or financial structure, should engage in public disclosure of its sustainable programs and efforts. Overall, non-profit sustainability reporting will attract the right talent and donors, save money, reduce the global collective footprint, and provide NGOs with a greater degree of leverage in large projects. Although issuing sustainability reports requires a great deal of work, there is strong evidence that sustainability reporting offers a number of financial and social advantages that far outweigh its costs. Respondents from organisations that publish sustainability reports identified data-related issues as among their most common challenges in the reporting process (Boston College Centre for Corporate Citizenship and Ernst \& Young, 2013).

Finally, this research also shows that it is important for NGOs to deliver their sustainability reports digitally, because stakeholders use the internet as a search tool to account for their donations. With the ' 5 per thousand' mechanism, NGOs have a responsibility to make donors confident by demonstrating that the donated amounts are being invested wisely. Donors have a right to know where and how their donations are being used. They also have a right to assess the organisational governance and functional reliability of the NGO to which they have donated. Sustainability reporting, which is not currently implemented by many of the 100 most-funded NGOs in Italy, is a future imperative for providing socially value-added impact. Findings reveal that, although there is a significant need for financing social projects, the ratio between investment in the form of donations and expected results remains rather vague. Sustainability reporting could bridge this gap, thus advancing NGOs' currently unsustainable profile.

\section{References}

Adams, C. (2017). Understanding integrated reporting: The concise guide to integrated thinking and the future of corporate reporting. London: Routledge. Argenti, P., \& Saghabalyan, A. (2017). Reputation at risk: The social responsibility of NGOs. Corporate Reputation Review, 20(1), 1-26.

Agenzia Entrate. (2018). http://www.agenziaentrate.gov.it/ wps/content/nsilib/nsi/archivio /archivio+5permille Accessed 10 February 2018.

Anheier, H., Haß, R., Then, V., Beller, A., \& Wehrsig, S. (2011). Accountability \& transparency: A comparative study of German non-profit organisations, public agencies and for-profit corporations. In A collaborative project of the Hertie School of Governance (HSoG) and the Centre for Social Investment (CSI) of Heidelberg University (pp. 1-5).

Arenas, D., Lozano, J. M., \& Albareda, L. (2009). The role of NGOs in CSR: Mutual perceptions among stakeholders. Journal of Business Ethics, 88(1), 175-197. Badelt, C., Meyer, M., \& Simsa, R. (1999). Handbuch der nonprofit organisation: Strukturen und management. Schäffer-Poeschel Verlag. 
Baumgartner, R. J., \& Rauter, R. (2017). Strategic perspectives of corporate sustainability management to develop a sustainable organisation. Journal of Cleaner Production, 140, 81-92.

Behn, B. K., DeVries, D. D., \& Lin, J. (2010). The determinants of transparency in nonprofit oganisations: An exploratory study. Advances in Accounting, 26(1), 6-12.

Berthelot, S., Coulmont, M., \& Serret, V. (2012). Do investors value sustainability reports? A Canadian study. Corporate Social Responsibility and Environmental Management, 19(6), 355-363.

Boiral, O. (2013). Sustainability reports as simulacra. A counter-account of A and A+ GRI reports. Accounting, Auditing E Accountability Journal, 26(7), $1036-1071$.

Bolton, E. B., \& Guest-Jelley, A. (2012). Working with non-profit organisations in community settings: Governance, accountability and transparency. University of Florida, IFAS Extension.

Boston College Center for Corporate Citizenship and Ernst \& Young (2013). Value of sustainability reporting. A study by Ernst \& Young LLP and the Boston College Center for Corporate Citizenship, Ernst \& Young.

Brown, H. S., de Jong, M., \& Levy, D. L. (2009). Building institutions based on information disclosure: Lessons from GRI's sustainability reporting. Journal of Cleaner Production, 17(6), 571-580.

Browne, J., \& Nuttall, R. (2013). Beyond corporate social responsibility: Integrated external engagement. The McKinsey Quarterly, 1-11.

BSR, GlobeScan (2011). State of sustainable business Poll 2011. BSR.

Bushman, R. M., \& Smith, A. J. (2003). Transparency, financial accounting information, and corporate governance. Economic Policy Review, 9(1), 1-23.

Cabedo, J. D., Fuertes-Fuertes, I., Maset-LLaudes, A., \& Tirado-Beltrán, J. M. (2018). Improving and measuring transparency in NGOs: A disclosure index for activities and projects. Nonprofit Management and Leadership, 28(3), 329.

Colombo, G., \& Gazzola, P. (2014). Ethics and CSR: The strategy debate. Confluências| Revista Interdisciplinar de Sociologia e Direito, 16(1), 84-98.

Costa, E., \& Pesci, C. (2016). Social impact measurement: Why do stakeholders matter? Sustainability accounting. Management and Policy Journal, 7(1), 99-124.

Crespy, C. T., \& Miller, V. V. (2011). Sustainability reporting: A comparative study of NGOs and MNCs. Corporate Social Responsibility and Environmental Management, 18(5), 275-284.

Dumay, J., Guthrie, J., \& Farneti, F. (2010). GRI sustainability reporting guidelines for public and third sector organisations: A critical review. Public Management Review, 12(4), 531-548.

Ernst \& Young (2012). Six growing trends in corporate sustainability. EYGM Limited. http://www.ey.com/Publication/vwLUAssets/Six-growing-trends-incorporate-sustainability/\$File/Six-growing-trends-in-corporate-sustainability.pdf Accessed 15 December 2017.

Freeman, R. E. (1984). Strategic management: A stakeholder approach. Boston: Pitman.

Friedman, A., \& Miles, S. (2006). Stakeholders: Theory and practices. Oxford: Oxford University Press.

Gazzetta Ufficiale. (2006). http://www.gazzettaufficiale.it/eli/id/2006/01/27/06A00865/sg Accessed 20 November 2017.

Gazzola, P. (2012). CSR per scelta o per necessità. Santarcangelo di Romanga (RN): Maggioli Editore.

Gazzola, P., \& Ratti, M. (2014). Transparency in Italian non-profit organisations. Annals of the University of Oradea, Economic Science Series, 23(1), 49-56.

Gazzola, P., \& Meo Colombo, C. (2011). The role of the sustainability report in capitalistic firm. Annals of the University of Oradea, Economic Science Series, 20 (2), 243-250.

Gazzola, P., Ratti, M., \& Amelio, S. (2017). CSR and sustainability report for non-profit organisations. An Italian best practice. Management Dynamics in the Knowledge Economy, 5(3), 355-376.

GRI. (2010). NGO sector disclosure. Global Reporting Initiative. https://www.globalreporting.org/resourcelibrary/GRI-G4-NGO-Sector-Disclosures.pdf Accessed 18 November 2017.

GRI (2011). Sustainability reporting: How valuable is the journey? Starting Points. Amsterdam: Global Reporting Initiative.

Hielscher, S., Winkin, J., Crack, A., \& Pies, I. (2017). Saving the moral capital of NGOs: Identifying one-sided and many-sided social dilemmas in NGO accountability. Voluntas: International Journal of Voluntary and Nonprofit Organisations, 28(4), 1562-1594.

Ionescu-Somers, A., \& Enders, A. (2012). How Nestlé dealt with a social media campaign against it. Financial Times. December 3. http://www.ft.com/intl/cms/ s/0/90dbff8a-3aea. Accessed 20 January 2018.

Ivanenko, Y. (2015). Economic definition of non-profit organisation. Actual Problems in Economics, 167, 8-19.

Joseph, G. (2012). Ambiguous but tethered: An accounting basis for sustainability reporting. Critical perspectives on Accounting, 23(2), 93-106.

Kanter, R. M., \& Summers, D. V. (1987). Doing well while doing good: Dilemmas of performance measurement in non-profit organisations and the need for a multiple-constituency approach. In W. W. Powell (Ed.), The non-profit sector - A research handbook (pp. 154-164). New Haven CT: Yale University Press.

Keating, V. C., \& Thrandardottir, E. (2017). NGOs, trust, and the accountability agenda. The British Journal of Politics and International Relations, 19(1), $134-151$.

Koppell, J. G. (2010). World rule: Accountability, legitimacy, and the design of global governance. Chicago: University of Chicago Press.

Lehman, G. (2007). The accountability of NGOs in civil society and its public spheres. Critical Perspectives on Accounting, 18(6), 645-669.

Lodi, G. (2012). 5 per mille. Dental Cadmos, 80(2), 57. 57.

Manetti, G. (2011). The quality of stakeholder engagement in sustainability reporting: Empirical evidence and critical points. Corporate Social Responsibility and Environmental Management, 18(2), 110-122.

Meyer, B., Ferrari, D., \& Zoebeli, D. (2012). Transparency of NPOs' financial reporting: A quantitative study of annual reports (Switzerland). In Democratization, marketization, and the third sector, 10 (pp. 1-14). http://c.ymcdn.com/sites/www.istr.org/resource/resmgr/wp2012/b_meyer.pdf. Accessed 20 November 2017.

Michelon, G., Pilonato, S., \& Ricceri, F. (2015). CSR reporting practices and the quality of disclosure: An empirical analysis. Critical Perspectives on Accounting, 33, 59-78.

Momin, M. A. (2013). Social and environmental NGOs' perceptions of corporate social disclosures: The case of Bangladesh. Accounting Forum, 37(2), $150-161$.

Morhardt, J. E., Baird, S., \& Freeman, K. (2002). Scoring corporate environmental and sustainability reports using GRI 2000 , ISO 14031 and other criteria. Corporate Social Responsibility and Environmental Management, 9(4), 215-233.

Morsing, M., \& Schultz, M. (2006). Corporate social responsibility communication: Stakeholder information, response and involvement strategies. Business Ethics: A European Review, 15(4), 323-338.

Newson, M., \& Deegan, C. (2002). Global expectations and their association with corporate social disclosure practices in Australia, Singapore, and South Korea. The International Journal of Accounting, 37(2), 183-213.

O’Dwyer, B., Unerman, J., \& Bradley, J. (2005). Perceptions on the emergence and future development of corporate social disclosure in Ireland: Engaging the voices of non-governmental organisations. Accounting, Auditing \& Accountability Journal, 18(1), 14-43.

Parsons, C. (2017). The (in)effectiveness of voluntarily produced transparency reports. Business E' Society, July, 1-29.

Radinger, G. (2017). My taxes go to NGOs! Centre for Philanthropy. Vienna: ERSTE Foundation.

Rauh, K. (2010). NGOs, foreign donors, and organisational processes: Passive NGO recipients or strategic actors? McGill Sociological Review, 1, 29.

Reimann, K. D. (2017). Up to no good? Recent critics and critiques of NGOs. In H. F. Carey (Ed.), Subcontracting peace (pp. 37-53). London: Routledge.

Rey, G. M., Álvarez Acebrón, G. L. I., \& Bello, L. (2013). The untapped potential of marketing for evaluating the effectiveness of nonprofit organizations: A framework proposal. International Review on Public and Nonprofit Marketing, 10(2), 87-102.

Rodríguez, M. D. M. G., Pérez, M. D. C. C., \& Godoy, M. L. (2012). Determining factors in online transparency of NGOs: A Spanish case study. VOLUNTAS: International Journal of Voluntary and Nonprofit Oganisations, 23(3), 661-683.

Salamon, L. M., \& Anheier, H. K. (1997). Defining the nonprofit sector: A cross-national analysis. Manchester: Manchester University Press. 
Saxton, G. D., \& Guo, C. (2011). Accountability online: Understanding the web-based accountability practices of nonprofit organisations. Nonprofit and Voluntary Sector Quarterly, 40(2), 270-295.

Simnett, R., Vanstraelen, A., \& Chua, W. F. (2009). Assurance on sustainability reports: An international comparison. The Accounting Review, 84(3), 937-967.

Striebing, C. (2017). Professionalization and voluntary transparency practices in nonprofit oganisations. Nonprofit Management and Leadership, 8(1), 65-83. Tremblay-Boire, J., \& Prakash, A. (2015). Accountability. org: Online disclosures by US nonprofits. VOLUNTAS: International Journal of Voluntary and Nonprofit Organisations, 26(2), 693-719.

Unerman, J., Bebbington, J., \& O’Dwyer, B. (2010). Introduction to sustainability accounting and accountability. In D. Gibassier \& J. Unerman (Eds.), Sustainability accounting and accountability (pp. 20-35). London: Routledge.

Valencia, L. A. R., Queiruga, D., \& González-Benito, J. (2015). Relationship between transparency and efficiency in the allocation of funds in nongovernmental development organisations. Voluntas: International Journal of Voluntary and Nonprofit Organisations, 26(6), 2517-2535.

Vlad, S. (2012). The motivation and ways of motivating the human resources - Best Western Hotel Central Arad. The Annals of the University of Oradea Economic Sciences XXI, 398-404.

Will, M. G., \& Pies, I. (2017). Discourse failures and the NGO sector: How campaigning can undermine advocacy. Voluntas: International Journal of Voluntary and Nonprofit Organisations, 28(3), 1078-1109.

Willetts, P. (2010). Non-governmental organisations in world politics: The construction of global governance. Routledge.

Yesudhas, R. (2019). Towards an era of official (involuntary) accountability of NGOs in India. Development in Practice, 29(1), 122-127.

Zainon, S., Hashim, M., Yahaya, N., \& Atan, R. (2013). Annual reports of non-profit organisations (NPOs): An analysis. Journal of Modern Accounting and Auditing, 9(2), 183.

Zald, M. N. (2017). Social movements in an organisational society: Collected essays. London: Routledge. 